\section{O telejornal e a telenovela: - discurso realidade-ficção}

\author{
Silmara Cristina Dela-Silva
}

\section{Resumo}

Este trabalho apresenta uma análise de discursos de mesmo tema, presentes em telejornais e telenovelas, programas que se propõem a apresentar, respectivamente, a realidade e a ficção na TV. As análises da linguagem e dos processos de produção de sentido no telejornalismo e na telenovela têm como ponto de partida notícias exibidas pelo Jornal Nacional e cenas transmitidas pela telenovela $O$ Clone, ambas produções da Rede Globo de Televisão. O objetivo é identificar como se constituem realidade e ficção nesses discursos televisivos, seja por meio da presença da ficção da telenovela no telejornalismo ou da inserção de temas reais, noticiados pelos jornais, nos capítulos da obra de ficção.

Palauras-chave:

Telejornalismo, Telenovela, Realidade, Ficção

\section{Newscast and soap opera: the fiction-reality discourse}

\section{Abstract}

This paper aims to analyze discourses. Howthe same theme is presented on news programs and in soap operas produced in Brazil? Programs that are intended to show, respectively, reality and fiction on TV. The selected objects of analysis are $O$ Clone soap opera and the Jornal Nacional TV news, both broadcasted by Rede Globo de Televisão. It investigates the language and the process of making sense from these TV productions. Its goal is to identify how reality and fiction are constituted on these programs, considering the existence of soap opera fiction on news programs and of the facts related to reality on Brazilian soap operas.

Key words:

TV broadcast journalism, Brazilian soap opera, Reality, Fiction 
Foi um momento de cumplicidade catártica absoluta com os telespectadores: a representação da vida deixou de ser apenas representação para ser a própria vida. Todas as distâncias entre ficção e "vida real" - aqui entendida como mundo empírico, fora da tela - foram apagadas. A telenovela virou "reportagem", assim como os telejornais, naqueles dias, viraram os capítulos mais "quentes" da telenovela. (Arbex Jr., 2001: 45-46) ${ }^{2}$

Este trabalho se propõe a pensar o jornalismo televisivo brasileiro e as suas relações com as telenovelas por meio da análise da linguagem e de seus processos de produção de sentidos. Interessa-se, de forma mais específica, por analisar discursivamente o processo pelo qual a notícia passa a ser parte do espetáculo televisivo, ao ser integrada como um tema de discussão à ficção da telenovela, bem como a transposição de temas tratados pelo jornalismo para cenas de telenovelas. ${ }^{1}$

Programas televisivos representativos dos gêneros informação e entretenimento, telejornal e telenovela se distinguem pela proposta de apresentação da realidade e da ficção na tevê, respectivamente. A fronteira entre o real e o fictício, no entanto, adquire mobilidade, a partir do momento em que fatos jornalísticos noticiados pelo telejornal são retomados pelos personagens da narrativa de ficção, e situações fictícias vividas por personagens da telenovela dão origem a pautas para o noticiário, de forma a retomar discursos em circulação na sociedade, em determinado momento histórico.

Esta proximidade entre realidade e ficção, com a presença nas telenovelas de fatos que se tornam notícia nos telejornais, manifesta-se de forma privilegiada no Jornal Nacional, exibido em horário nobre pela Rede Globo de Televisão, e nas telenovelas historicamente nomeadas "novelas das 8", transmitidas após o noticiário, de segunda-feira a sábado. Um dos mais antigos noticiários da televisão brasileira e o primeiro programa a ser transmitido em rede para todo o país, o Jornal Nacional é assistido diariamente por mais de $40 \mathrm{mi}$ lhões de pessoas, segundo estimativas da emissora, um público que, em sua maioria, também é telespectador das telenovelas exibidas após o seu término.

Embora seja elaborado para apresentar notícias, produto jornalístico que relata fatos considerados de interesse do público, o telejornal, e especificamente o Jornal $N a$ cional, acaba se apropriando de histórias e relatos abordados primeiramente por programas de ficção, como as telenovelas. De forma semelhante, também as telenovelas inserem em suas narrativas assuntos em pauta nos noticiários. Este fenômeno parece ter início na década de 1990 e constitui-se como prática recorrente na produção televisiva brasileira.

A telenovela Duas Caras, exibida desde outubro de 2007 pela Rede Globo, após o Jornal Nacional, inseriu em sua narrativa, dentre outras temáticas, o uso irregular de cartões corporativos pela personagem Branca, interpretada pela atriz Susana Vieira. A trama traz para o plano da ficção as denúncias de uso irregular do cartão corporativo por funcionários do alto escalão do governo federal, em destaque nos noticiários de política desde o final do mês de janeiro de 2008. Na telenovela, a personagem Branca, que é uma das diretoras de uma universidade, utiliza o cartão corporativo para custear
${ }^{1}$ Este artigo apresenta reflexões teóricas e resultados da dissertação de mestrado "A realidade-fiçção do discurso televisivo" (Programa de Pós-Graduação em Estudos Lingüisticos - Unesp). Parte do resultados da pesquisa foram apresentados no XIX Enanpoll

Encontro Nacional de PósGraduação e Pesquisa em Letras e Lingüistica no XXX Congresso Brasileiro de Ciências da Comunicação - Intercom 2007

${ }^{2}$ Sobre a cobertura do Jornal

Nacional e da telenovela De corpo e alma ao assassinato da atriz Daniela Perez, uma das protagonistas da trama, em 29 de dezembro de 1992

${ }^{3}$ Neste trabalho, o discurso é considerado enquanto "efeito de sentido entre locutores" (Pêcheux,

1997), ponto de encontro entre uma atualidade e uma memória (Pêcheux, 1990). Desta forma, o discurso retoma dizeres e desloca

ou perpetua sentidos em um determinado momento histórico. Para a compreensão dos discursos,

faz-se necessário a observação não apenas da linguagem, mas

das chamadas condições de produção, que compreendem tanto os elementos restritos à enunciação, como os sujeitos e a situação, quanto às circunstâncias mais amplas de sua produção, como os contextos sócio-histórico e ideológico.

\section{Estudos em Jornalismo e Mídia}


despesas pessoais, como presentes para o namorado. A prática irregular é descoberta nos capítulos exibidos em meados do mês de março, após investigação sobre as compras realizadas com os cartões da universidade, realizada a pedido da personagem Célia Mara, interpretada por Renata Sorrah, também membro da direção da universidade e inimiga declarada de Branca. Neste caso, é a telenovela que passa a desenvolver em suas tramas assuntos que fizeram parte da pauta dos noticiários e que permanecem atuais, uma vez que as denúncias resultaram na criação de uma Comissão Parlamentar de Inquérito (CPI) para a apuração das irregularidades, no final de fevereiro.

O exemplo acima mostra como telejornal e telenovela apresentam o que neste trabalho é inicialmente tratado como realidade e ficção, seja pelo paralelismo temático, seja pela forma de narração das histórias e dos fatos. Sem alcançar a isenção total dos relatos apresentados, a abordagem supostamente imparcial do noticiário é acrescida do tratamento explícito e interpretativo dos fatos noticiados durante os capítulos da telenovela, o que suscita questionamentos sobre a presença dos elementos de ficção nos relatos de fatos reais, e da realidade nas histórias de ficção.

Para analisar discursivamente esta relação entre telejornal e telenovela, entre realidade e ficção, este trabalho adota como ponto de partida notícias e cenas exibidas, respectivamente, pelo Jornal Nacional e pela telenovela $O$ Clone, entre outubro de 2001 e junho de 2002. Os trechos de programação foram selecionados a partir da gravação diária do telejornal e do capítulo da telenovela, observados de forma a identificar trajetos temáticos constituídos entre os dois programas. Como os capítulos da telenovela são produzidos previamente, os temas tratados pelo telejornal encontram reflexo na obra de ficção apenas alguns dias depois. Da mesma forma, as discussões iniciadas pelos personagens da telenovela podem se transformar em pauta para as matérias jornalísticas transmitidas pelo noticiário da mesma emissora nos dias seguintes.

As análises são realizadas de acordo com os pressupostos teóricos e metodológicos da Análise de Discurso de cunho materialista, perspectiva de estudos que privilegia a análise das relações entre a língua, os sujeitos e as condições históricas para a compreensão de como a linguagem, e neste caso específico a linguagem jornalística, constitui sentidos (Pêcheux, 1990, 1997; Orlandi, 2001). Em vez de perseguir os objetivos da televisão ao constituir sentidos com mesmos trajetos temáticos no telejornal e nas telenovelas, reforçando a oposição entre realidade e ficção, este trabalho busca compreender como os sentidos são constituídos nestes programas televisivos distintos.

Este artigo encontra-se dividido em duas partes: na primeira, apresenta algumas considerações históricas sobre o telejornalismo e a produção de telenovelas; na segunda parte, apresenta os conceitos teóricos mobilizados, os procedimentos analíticos e algumas análises que buscam compreender a relação entre realidade e ficção que constitui o discurso televisivo. Ao identificar as diferenças e as semelhanças entre os programas analisados, com relação à constituição dos discursos e à textualidade, a análise também busca possibilitar ao profissional do jornalismo elementos para a reflexão sobre a prática de 
produção das notícias e as conseqüências para esta prática da proximidade entre os discursos do telejornal e da telenovela.

\section{Telejornal e telenovela:}

\section{proximidades e/ou distanciamentos}

A relação entre realidade e ficção coloca-se de diferentes formas no jornalismo, desde as suas primeiras publicações diárias, em meados do século XIX. Por volta de 1840, publicações francesas incorporam a narrativa literária aos jornais como forma de destinar a produção jornalística ao grande público, servindo-se para isto dos folhetins. Forma de preenchimento para o rodapé dos jornais, os folhetins funcionam como uma nova proposição de mundo, e complementam a edição dos periódicos franceses da época (Meyer, 1996).

Juntamente à publicação de anúncios pagos, os folhetins que são adotados como estratégia para impulsionar as tiragens dos primeiros periódicos também aproximam as narrativas de ficção dos relatos jornalísticos, produzidos com base em acontecimentos da realidade, ao ocupar espaços destinados originalmente ao dizer sobre os fatos. São ainda os folhetins que se tornam os precursores das radionovelas e, posteriormente, das telenovelas, ao inspirar nas novas mídias a prática do contar romances em forma de histórias seriadas.

Produzida para um público específico, sob condições sócio-históricas e ideológicas distintas daquelas dos folhetins publicados no século XIX, a telenovela resgata uma memória discursiva sobre as narrativas de ficção, ainda que constitua seu próprio discurso, influenciada pela história de seu desenvolvimento no país e por seus objetivos junto ao público. As primeiras te-

A telenovela,
mesmo sendo um
gênero de ficção,
manifesta-se como
uma continuidade
da experiência
de vida de seus
telespectadores,
uma vez que ela
exibe em suas
narrativas os
acontecimentos
da forma como
o público está
acostumado a
presenciar

Estudos em Jornalismo e Mídia Ano V № 1 - 10 semestre de 2008 lenovelas brasileiras, segundo Fernandes (1994), exibidas no início da década de 1960, trazem para o telespectador as temáticas desenvolvidas pelos folhetins e pelas radionovelas, em histórias com foco em relações amorosas e familiares. Marcondes Filho (1994) considera que a produção televisiva desta época caracteriza-se por apresentar o mundo, ao transmitir programas ao vivo e priorizar narrativas provenientes de adaptações literárias.

Uma nova fase da televisão, segundo o autor, tem início na década de 1980, e resulta em uma nova relação entre realidade e ficção nas telenovelas. No que Marcondes Filho considera a segunda fase da televisão brasileira, tem início a transmissão de programas televisivos que visam a simular o mundo. Desde então, autores assumem em suas histórias fictícias o propósito de colocar em discussão assuntos polêmicos e debates sobre a atualidade do país. Com isso, a telenovela continua a se constituir em oposição a uma realidade objetiva, mas com a proposta de apresentar histórias que poderiam acontecer com os próprios telespectadores, com a recuperação de discussões iniciadas nas esferas pública e privada da sociedade em que são produzidas. É a partir deste período que as telenovelas alcançam maior público e passam a fazer parte do cotidiano das pessoas, ao exibir em suas histórias experiências do dia-a-dia.

Em seus estudos, Kehl (1986) afirma que a telenovela, mesmo apresentandose como um gênero de ficção, manifestase como uma continuidade da experiência de vida de seus telespectadores, uma vez que ela exibe em suas narrativas os acontecimentos da forma como o público está acostumado a presenciar. Segundo a 
${ }^{4}$ Na dissertação de mestrado "A realidade-ficção do discurso televisivo", além de um estudo mais detalhado dos trajetos temáticos "Falsificacão e contrabando" e "Uso e tráfico de drogas", são apresentadas as análises de um terceiro trajeto temático que trata da clonagem, ponto central da discussão proposta pela telenovela. autora (Kehl, 1986: 284), "o real é aquilo que se mostra; aquilo que se evidencia porque assume formas velhas conhecidas. A realidade é uma convenção de iluminação". Ao considerar o caráter de complementação que a telenovela confere às experiências diárias dos telespectadores, Kehl estabelece uma tênue fronteira entre a realidade objetiva do telespectador e as histórias da telenovela.

Em oposição às histórias fictícias apresentadas pelas telenovelas, o telejornalismo reúne características da imprensa em geral, que incluem o "relato objetivo" dos fatos, por meio da produção de um discurso em que o sujeito é o próprio fato relatado. As reportagens buscam a imparcialidade, com a produção de textos livres de partículas capazes de atribuir valores e interpretações aos fatos, como os adjetivos, por exemplo, ou as narrativas em primeira pessoa. Como na telenovela, o noticiário para a televisão parte do pressuposto de que existe um real objetivo que pauta o fazer jornalístico. A missão do telejornal é buscar o fato - matéria-prima do jornalismo - e apresentá-lo ao telespectador da forma mais fiel possível ao acontecimento.

A relação de proximidade entre realidade e ficção, no entanto, também produz efeitos nos jornais e, de forma particular, nos telejornais, que passam a se apropriar de histórias inicialmente presentes nas telenovelas, como pauta ou mesmo complemento a reportagens. Com a interação e a transposição temática entre o real jornalístico e a ficção das novelas, estes programas, aos poucos, adquirem características comuns. Os discursos do telejornal e da telenovela, em conseqüência, constituem-se mutuamente. Esta transposição temática entre telejornal e telenovela marca-se discursivamente, nos sentidos produzidos a partir do funcionamento da linguagem jornalística e da telenovela.

$\mathrm{Na}$ perspectiva teórica em que se insere, este trabalho assume que a compreensão do discurso do telejornal e da telenovela passa não apenas pela consideração da linguagem verbal empregada, mas também pela memória da televisão e da sociedade, quesitos privilegiados conjuntamente. Para a realização das análises, fez-se necessário a constituição de um corpus de pesquisa, composto por notícias exibidas pelo telejornal e cenas da telenovela, e a constituição de um dispositivo de análise, a partir do contato prévio com o corpus, de forma a permitir a compreensão de seu funcionamento. Dentre os conceitos disponibilizados pela Análise de Discurso, compõem o dispositivo analítico as noções de designações, formações imaginárias, memória discursiva e a relação entre paráfrase e polissemia. Tais conceitos teóricos serão especificados na próxima seção, associados às análises dos recortes realizados.

\section{A realidade-ficção da tevê: uma análise}

Para compreensão do funcionamento do discurso com mesma temática, em circulação no telejornal e na telenovela, serão apresentadas nesta seção breves análises de parte de duas das temáticas identificadas após o estudo da telenovela $O$ Clone e das edições do Jornal Nacional exibidas à época, a saber: falsificação e contrabando de mercadorias, e uso e tráfico de drogas ${ }^{4}$.

Para o procedimento analítico, foram realizados recortes no corpus de análise, de forma a identificar os trajetos temáticos coincidentes no telejornal e na telenovela considerados. Para tanto, foram realizadas 
inicialmente gravações das edições diárias do noticiário e dos capítulos da telenovela. Numa segunda etapa, foi identificada no material gravado a ocorrência de temas semelhantes. Durante a análise, buscou-se realizar a passagem do texto para o discurso, pensando sempre a relação entre a materialidade da linguagem e a exterioridade, as condições de produção dos discursos do telejornal e da telenovela. Os pontos de análise aqui apresentados centram-se em quatro questões teóricas principais: nas designações, nas formações imaginárias, nas memórias acionadas no processo discursivo e na relação entre paráfrase e polissemia, conforme especificados durante a apresentação das análises.

O trajeto temático sobre falsificação e contrabando marca-se a partir do telejornal, que exibe duas séries especiais de reportagens, a primeira delas intitulada "Fronteiras do Brasil", que trata mais particularmente da questão do contrabando em regiões fronteiriças, e a segunda denominada "Pirataria", prática apresentada pelo telejornal como uma conseqüência da entrada ilegal de mercadorias no país. Posteriormente, a discussão sobre o tema é incorporada à narrativa de ficção por meio da prática mal-sucedida de colocação de etiquetas falsas em camisas fabricadas por um dos personagens da trama, somada à divulgação, pelo telejornal, de notícias de apreensão de produtos falsificados.

Um primeiro ponto a ser observado nos recortes selecionados para análise são as designações empregadas pelo telejornal. Por designações compreende-se "a significação de um nome", construída simbolicamente, no momento histórico em que se realizam (Guimarães, 2002: 9). No recorte (1), são as designações que estabelecem a oposição en- tre os responsáveis pela venda de produtos falsificados - os vendedores ambulantes - e os falsificadores - aqueles que fazem a falsificação de produtos.

(1) Apresentador: A polícia paulista apreendeu hoje 8 mil CDs falsificados. Os CDs estavam em um carro, no trecho da via Dutra que corta a cidade de Guarulhos, na Grande São Paulo. Havia também dois gravadores e material para imprimir capa de discos. Dois homens foram presos. Vendedores ambulantes deram as pistas para que a polícia chegasse aos falsificadores. (Jornal Nacional - 04.04.2002)

Os falsificadores são primeiramente designados por homens, enquanto os vendedores dos produtos apreendidos, constituídos em uma formação imaginária ${ }^{5}$ de vítima da situação econômica do país, são denominados vendedores ambulantes. O distanciamento dos vendedores em relação aos falsificadores marca-se pela expressão deram pistas, que também projeta para os vendedores uma imagem positiva, de quem colabora para o trabalho policial de prisão dos responsáveis pela prática ilegal de falsificação.

As mesmas designações identificadas no discurso do telejornal estão presentes na telenovela $O$ Clone, em cuja narrativa são estabelecidas as imagens para o falsificador e o vendedor de produtos falsificados. O lugar do falsificador na telenovela é ocupado por cidadãos residentes na periferia do Rio de Janeiro, que passam a se dedicar à falsificação de mercadorias em busca do lucro. A telenovela, servindo-se da paráfrase - que consiste na repetição discursiva -, atualiza a imagem do vendedor de produtos
${ }^{5} \mathrm{O}$ conceito de formação imaginária é elaborado por Pêcheux (1997) para se referir às imagens que determinam o lugar que os sujeitos do discurso atribuem a si mesmos e ao outro durante a enunciação, bem como as ima-

gens que fazem do lugar que atribuem a si e ao outro. Desta forma, no funcionamento discursivo não são os próprios sujeitos,

enquanto seres humanos, que

participam dos processos de produção de sentidos, mas as imagens que projetam para si, para o outro e para o referente. Sobre formações imaginárias, ver também Orlandi (2001).

\section{Estudos em Jornalismo e Mídia}


falsificados já apresentada pelo telejornal - a do cidadão que se serve das fraudes e do comércio de produtos trazidos irregularmente para o país. Pelo processo de paráfrase, a telenovela retoma em seu discurso sentidos já presentes no telejornal, de forma a manter os mesmos processos de significação.

Ao utilizar-se das mesmas designações, mesmas formações imaginárias e recorrer ao procedimento de paráfrase para o funcionamento discursivo, a telenovela dá continuidade à discussão proposta pelo telejornal, como que ilustrando os fatos mostrados no noticiário. Nos recortes abaixo, exibidos quando a falsificação de camisas produzidas pelo alfaiate Edvaldo (Roberto Bonfim) feita pelos personagens Raposão, Ligeiro e Aninha é descoberta, os responsáveis pela prática ilegal são ameaçados tanto pelo produtor das camisas como pelos fornecedores das etiquetas falsificadas (identificados pela telenovela como máfia). A telenovela retoma, assim, o discurso moralizante de punição à ação ilegal, apresentado no telejornal, ainda que de forma não explícita.

(2) Raposão (mecânico): Alô, alô, o senhor tá querendo de volta as etiquetas falsificadas? O, o dinheiro que a gente tá devendo? Cara, são os china, é a máfia, tão ameaçando a gente, sujô. (...) Eles tão querendo as etiquetas falsificadas ou então o dinheiro que a gente tá devendo, ferrou, cara, ferrou... (Telenovela - 02.04.2002)

(3) Edvaldo (alfaiate): É que os dois ficam querendo ser muito espertos, é isso, tão sempre querendo ser muito espertos... Agora são intermediários como vocês é que são extorquidos por eles, entendeu, extorquidos pela máfia. Cara, isso é crime organizado, qual é? Sabe o que vai acontecer? Eles vão arrancar a grana de vocês todinha, todinha, e vocês ainda vão acabar presos. (Telenovela - 03.04.2002)

Ao tratar da falsificação e do contrabando, a telenovela retoma sentidos já privilegiados pelo noticiário, com a apresentação da relação entre o falsificador e a máfia, no recorte (2), e as possíveis conseqüências da ação ilegal para os responsáveis (3). O discurso da telenovela constitui, assim, as imagens do falsificador e do contrabandista; enquanto os primeiros são chamados de "intermediários", responsáveis pela venda de produtos ilegais, os "contrabandistas" - designados pelo termo "máfia" - são responsabilizados pela chegada de produtos ilegais no país.

Para tratar dos sujeitos que ocupam as posições de falsificador de mercadorias, contrabandistas e vítimas dessas ações, a telenovela emprega as designações intermediários, extorquidos pela máfia, malandros e espertos demais. Já os responsáveis pela comercialização de produtos pirateados apresentados pelo telejornal são nomeados pela forma genérica homens ou por vendedores. Os termos intermediários e extorquidos pela máfia trazem consigo a imagem de vítimas de uma situação irregular, embora no discurso jurídico o responsável pela venda de produtos falsificados seja considerado cúmplice do falsificador, co-responsável pelas ações em contrariedade à legislação (Código Penal Brasileiro, 07.12.1940).

No recorte (4), o alfaiate que tem os seus produtos falsificados estabelece o lugar de vítima para os responsáveis pela comercialização irregular - o lugar de intermediário, aquele que é usado pela máfia, os fornecedores do produto ilegal. 
(4) Edvaldo (alfaiate): ... Porque pirataria é crime, vocês não sabem disso não? Dá cadeia! Qual é, rapaz, isso é coisa de crime organizado, isso é coisa muito perigosa. Não lêem jornal? Todo dia tá saindo aí que tão falsificando CD, tão falsificando roupa, até programa de computador (...) Agora, são intermediários como vocês é que são extorquidos por eles, entendeu, extorquidos pela máfia... (Telenovela - 03.04.2002)

Ao constituir a imagem do falsificador como intermediário, vítima de um crime maior, a telenovela abre espaço para esses sujeitos. Como deixam de ser reconhecidos como simples infratores da lei, esses sujeitos adquirem o direito de se manifestar reservado às vítimas pelo discurso jurídico. Enquanto o contrabandista ocupa a posição daquele que burla a lei em busca de lucros, com desempenho facilitado graças à fiscalização deficitária nas fronteiras brasileiras, o falsificador é o desempregado, o cidadão que sem uma oportunidade profissional, dedica-se ao comércio ilegal para assegurar a sobrevivência da família, como reconhecido pelo próprio telejornal, com a nomeação subsistência no recorte (5):

(5) Repórter: A venda de produtos pirateados virou a única forma de subsistência para muitos. Bons lucros, a falsificação só garante a poucos. Prejuízos, ela traz a todos nós. (Jornal Nacional - 09.04.02)

Telejornal e telenovela inserem, assim, o discurso moralizante, em que agir de acordo com a lei é seguir os princípios morais. O discurso moralizante ou edificante é marcado durante toda a formulação discursiva, na telenovela e no telejornal - seja com a

Telejornal e
telenovela
inserem o discurso
moralizante, em
que agir de acordo
com a lei é seguir
os princípios
morais

morais "perseguição da máfia" aos personagens da telenovela que colocam etiquetas falsificadas em camisas produzidas por um alfaiate da periferia do Rio de Janeiro, seja pela perseguição policial aos contrabandistas nas fronteiras brasileiras ou aos falsificadores que fornecem produtos para a venda ilegal nas ruas das grandes cidades.

Embora pertençam a gêneros diferenciados de programas e tenham propostas distintas, a telenovela e o telejornal mantêm um diálogo permanente sobre a falsificação e o contrabando, que influencia na constituição de sentidos. De forma geral, o discurso televisivo no trajeto temático da falsificação e do contrabando de mercadorias aciona a memória discursiva sobre os crimes e as suas punições, própria do discurso jurídico, e se serve das designações características deste discurso jurídico, combinado a um discurso moralizante que perpassa as formulações. Com o discurso moralizante sendo formulado juntamente ao jurídico, com destaque para a necessidade de cumprimento das leis, telejornal e telenovela atualizam a dualidade entre bem e mal, com o bem sendo representado pelas leis e a moral, e o mal, em oposição, pelas ações que desrespeitam as normas jurídicas.

Ao contrário do trajeto temático sobre falsificação e contrabando, que transcende os limites do noticiário e chega à telenovela, ocorre o oposto com o segundo tema analisado, uso e tráfico de drogas: o trajeto temático se constitui inicialmente na telenovela e passa a constituir sentidos também no telejornal. A principal diferença entre os discursos do noticiário e da narrativa de ficção é que enquanto o telejornal apresenta o tráfico de drogas como uma ação criminosa, empregando designações sustentadas pelo 
discurso jurídico, a telenovela exibe o uso das drogas com enfoque na dependência provocada no usuário e no drama vivido pelos familiares, priorizando o discurso médico. É nessa relação entre o jurídico e o médico que telejornal e telenovela determinam as posições sujeito para o traficante, o usuário de drogas e o dependente químico.

Ao apresentar o uso de drogas com base na história de jovens dependentes químicos de classe média alta, a telenovela $O$ Clone constitui o lugar do usuário no momento histórico em que formula o seu discurso: jovens que não têm consciência de sua situação de dependência das drogas e, por isso, infringem a lei, usando as substâncias proibidas. Em apoio ao discurso jurídico, que proíbe o consumo de determinadas substâncias químicas, a telenovela aciona como interdiscurso a oposição entre as drogas e os bons costumes, um dizer formulado no início do século XIX, quando grupos religiosos iniciam o movimento em defesa da proibição das drogas, primeiramente nos Estados Unidos (Rodrigues, 2003). Esse já-dito constitutivo da formulação discursiva em análise está presente, por exemplo, nos recortes (6) e (7), que demonstram o drama familiar, a partir da simulação do dia-a-dia de duas famílias do Rio de Janeiro:

(6) Maisa (mãe): Pára e pensa, Lucas, vai ser um escândalo pros jornais. Neta de Leônidas Ferraz metida com drogas. Lucas, você ainda não viu a Mel no estado em que eu vi. Imagina uma foto daquelas estampada em todos os jornais, Lucas...

(7) Clarice (mãe): Eu não sei mais o que fazer com esse menino, Carol. A gente faz tudo pra se proteger numa cidade como essa, com medo da violência, com medo de sei lá o quê. Aí esse menino sai pela night e resolve trazer quem ele bem entende pra dentro de casa. Oh, Carol, essa menina podia ser uma assaltante. (Telenovela - 28.03.2002)

Os recortes (6) e (7) mostram a situação dos pais que não sabem o que fazer para impedir que os filhos utilizem as drogas ilícitas e as conseqüências do consumo ilegal para a vida das famílias. Instituição considerada berço da moral e dos bons costumes pelos grupos religiosos, a família é apresentada a partir da imagem de vítima da dependência química de seus membros. O discurso moralizante na telenovela é marcado em formas como neta e menino, ditas pelas mães dos jovens, que inserem no discurso a relação familiar comprometida pelas drogas.

As conseqüências do uso ilegal são reforçadas com o recorte (7), que enfatiza as repercussões da prática ilegal na sociedade trazida para a telenovela. Além da imagem de destruição das famílias que é atualizada pelo discurso, essa posição sujeito ocupada pelos familiares também se preocupa com o uso da ilegalidade em matérias jornalísticas (6), uma remissão aos noticiários que exibem, quase que diariamente, casos de apreensões de drogas pela polícia.

Pelo processo de paráfrase, com a busca pelo mesmo dizer, a telenovela constitui a imagem do traficante, determinada a partir do discurso das drogas como fator gerador de violência, o mesmo recurso adotado pelo telejornalismo. No recorte (8), o personagem Lobato (Osmar Prado) faz essa associação ao reconhecer que o dinheiro da venda ilegal de drogas é utilizado para a compra de armas e a transformação de crianças em futuros traficantes, tendo como marcas as expressões 
o dinheiro do meu trabalho, os barões do tráfico e soldadinhos do tráfico e a nomeação conivente para qualificar suas próprias ações.

(8) Lobato (dependente): Sim, eu protestava usando drogas, eu protestava fumando um baseado, mas só que eu não tava dizendo não à sociedade, eu tava dizendo não a mim (...) hoje, quando eu compro um baseado, quando eu cheiro uma carreira de pó, eu me sinto conivente com esse sistema, eu me sinto dando o dinheiro do meu trabalho para que os barões do tráfico comprem mais uma AR-15 pra entregar pros soldadinhos do tráfico, meninos de 13, 15 anos de idade, cuja perspectiva de vida não vai além dos 19 , eu me sinto conivente com essa violência que aí está, que me horroriza, que me assusta... (Telenovela - 01.04.2002)

Embora reconheça o consumo de drogas como uma doença, aspecto social enfatizado pela telenovela, o telejornalismo dá ênfase às conseqüências do uso para a sociedade. Como se trata de uma prática ilegal, condenada no discurso jurídico, o consumo dos dependentes químicos gera o tráfico de drogas - venda ilegal das substâncias químicas. O discurso do tráfico como gerador de violência é atualizado com a apresentação de reportagens em que a disputa entre traficantes resulta em um tiroteio em um dos bairros do Rio de Janeiro (9 e 10).

(9) Apresentador: Uma guerra de traficantes aterrorizou moradores de um bairro de classe média do Rio. O fim de semana também foi marcado pela violência em outros pontos da cidade.

(10) Repórter: Mas as cenas de guerra

\section{Ao constituírem sentidos \\ conjuntamente, os discursos \\ do telejornal e da telenovela adquirem \\ características comuns, tornando-se uma espécie de discurso realidade-ficção}

aconteceram mesmo ontem à noite, aqui na Tijuca. Esse é um bairro tradicional, com edifícios de classe média, mas cercado por favelas, dominadas por traficantes, segundo a polícia. Duas quadrilhas rivais, de favelas vizinhas, entraram em guerra... (Jornal Nacional - 01.04.2002)

Ao associar o uso de drogas a uma prática ilegal que gera violência, com o relato da disputa entre traficantes como provocadora de uma guerra urbana no Rio de Janeiro, o telejornal aciona a mesma memória da telenovela, que atribui ao dinheiro do usuário de drogas a responsabilidade pelo fortalecimento do tráfico no país. Os sentidos perpassam as matérias jornalísticas e as cenas da telenovela, com a guerra provocada pelos traficantes exemplificando o lado negativo das drogas, comentado pelo personagem da ficção que tenta se livrar da dependência, dando continuidade na telenovela ao discurso formulado pelo noticiário.

Ao constituírem sentidos conjuntamente, os discursos do telejornal e da telenovela adquirem características comuns, tornando-se uma espécie de discurso realidade-ficção, resultante de processos discursivos semelhantes. Os processos discursivos marcam-se pelo emprego de mesmas designações, pelo resgate de uma mesma memória discursiva e pela projeção de imagens semelhantes para os sujeitos do discurso. Em termos de efeitos de sentido, os discursos do telejornal e da telenovela, desta forma, constituem-se mutuamente.

\section{Considerações Finais}

A análise de trajetos temáticos que perpassam o telejornalismo e a telenovela aponta que, embora sejam programas com 
com objetivos diferentes e estruturas distintas, telejornal e telenovela compõem discursos complementares, que constituem sentidos conjuntamente. Este efeito de sentido que se constrói na junção entre os discursos do telejornal e da telenovela é o que aqui é nomeado discurso realidade-ficção, uma vez que os sentidos que produz são constituídos entre as narrativas de ficção e os relatos de fatos jornalísticos.

$\mathrm{Na}$ análise, destacam-se ao menos cinco mecanismos comuns aos processos discursivos da telenovela e do telejornal: a busca pelo sentido único com o predomínio da paráfrase sobre a polissemia, a retomada de uma mesma memória discursiva, o uso de designações comuns e as formações imaginárias semelhantes sobre os sujeitos do discurso. Além disso, os discursos nos trajetos temáticos analisados têm o discurso moralizante como constitutivo, atualizado pelo telejornal e também pela telenovela.

É por meio da designação, primeiramente, que o telejornal estabelece a diferença entre o traficante e o usuário de drogas, o falsificador, o vendedor de mercadorias falsificadas e o contrabandista. Ao classificar os responsáveis por atos criminosos como bandidos, falsificadores, contrabandistas e traficantes, termos característicos do juridismo, o noticiário reserva o lugar da inconformidade com a lei, da contrariedade à legislação do país aos personagens apresentados durante as reportagens. Além das mesmas designações, a telenovela também insere em seu discurso termos como máfia e intermediários, que preservam o sentido de infração às leis.

As imagens dos sujeitos dos discursos e dos acontecimentos também determinam a forma como um processo discursivo constitui sentidos. Na constituição dos sentidos dos discursos de falsificação e contrabando e de uso e tráfico drogas, são as projeções imaginárias que definem o lugar do traficante e do contrabandista - em desacordo com a legislação - e do falsificador e do usuário de drogas - vítimas do sistema socioeconômico vigente e da ação dos traficantes, respectivamente.

Os lugares são destinados aos sujeitos e aos acontecimentos no discurso televisivo de forma a acionar uma memória discursiva. A memória discursiva - conjunto dos dizeres sobre determinados assuntos que significaram em uma situação dada - retoma um já-dito que permite a compreensão do funcionamento dos discursos e de suas relações com a ideologia. Ao trazer o discurso da falsificação e do contrabando de mercadorias, o telejornal e a telenovela retomam sentidos já estabilizados para as ações retratadas, atualizando as discussões para elaboração da legislação brasileira sobre o assunto. A partir da definição jurídica para a falsificação e o contrabando, noticiário e telenovela resgatam a imagem de criminoso para os responsáveis pelas ações, a memória jurídica sobre o assunto.

O mesmo acontece com o discurso televisivo sobre o uso e o tráfico de drogas, cuja memória discursiva resgata a história de proibição do uso de drogas e as determinações legais para impedir e punir o tráfico. $\mathrm{O}$ discurso das drogas também atualiza a literatura médica de classificação das substâncias e dos seus efeitos no organismo, com a associação do uso das drogas de consumo proibido à dependência química, uma doença, de acordo com a medicina.

Ao retomar uma mesma memória discursiva, acionando formações imaginárias semelhantes sobre os sujeitos do discurso e os acontecimentos, com mesmas designações, telenovela e telejornal buscam um sentido único 
para o discurso sobre o uso e o tráfico de drogas e a falsificação e o contrabando de mercadorias, com um processo discursivo em que predomina a paráfrase sobre a polissemia. Com a paráfrase em funcionamento, os programas silenciam em seus discursos novos sentidos que também constituem os episódios relatados, como as causas da falsificação e do contrabando de mercadorias e a proibição ao consumo de drogas como fator gerador do tráfico dessas substâncias.

Ao constituir sentidos por meio da telenovela e do telejornal a partir de discursos que partem de formações imaginárias semelhantes, priorizando a paráfrase à polissemia, recuperando uma mesma memória discursiva para as tematizações e servindo-se de designações comuns, a televisão reúne realidade e ficção em seu discurso. Com a combinação entre o real e a ficção, telejornal e telenovela constituem conjuntamente os sentidos para os acontecimentos cotidianos, embora se proponham a apresentar narrativas fiéis aos fatos ocorridos diariamente, no caso do telejornal, e histórias criadas do imaginário, no caso das telenovelas.

As análises desenvolvidas apontam que para a compreensão do funcionamento discursivo do telejornal e da telenovela faz-se necessário afastar a simples oposição entre realidade e ficção, e buscar compreender os efeitos discursivos, com a observação das formações imaginárias e das condições de produção desses discursos. Para o profissional do jornalismo, a proximidade discursiva entre realidade e ficção na tevê propõe a reflexão sobre os limites do fazer jornalístico e a sua ancoragem em uma suposta realidade objetiva. Mostrarse como um retrato da realidade, um relato de acontecimentos, não exime o noticiário de tevê de ser parte do espetáculo televisivo.

\section{Sobre a autora}

Silmara Cristina Dela-Silva, Jornalista, Mestre em Estudos Lingüísticos pela Unesp, doutoranda em Lingüistica pela Unicamp, docente dos cursos de Comunicação Social do Imes-Fafica.

email: silmara.dela@uol.com.br

\section{Referências}

ARBEX JR., J. Showrnalismo: a notícia como espetáculo. São Paulo: Casa Amarela, 2001.

FERNANDES, I. Memória da telenovela brasileira. 3 ed. São Paulo: Brasiliense, 1994.

GUIMARÃES, E. Semântica do acontecimento. Campinas: Pontes, 2002.

KEHL, M.R. Três ensaios sobre telenovela. In: SIMÕES, I.F.; COSTA, A.H.; KEHL, M.R. Um país no ar: história da televisão brasileira em três canais. São Paulo: Brasiliense, 1986.

MARCONDES FILHO, C. Televisão. São Paulo: Scipione, 1994.

MATTELART, A.; MATTELART, M. O carnaval das imagens: ficção na TV. São Paulo: Brasiliense, 1989.

MEYER, M. Folhetim: uma história. São Paulo: Companhia das Letras, 1996.

ORLANDI, E.P. Análise de discurso. Princípios e procedimentos. $3^{a}$ edição, Campinas: Pontes, 2001.

PÊCHEUX, M. Análise automática do discurso (AAD-69). In: GADET, F.; HAK, T. (Org.) Por uma análise automática do discurso. 3a edição, Campinas: Editora da Unicamp, 1997.

. O discurso. Estrutura ou acontecimento. Campinas: Pontes, 1990.

RODRIGUES, T. Narcotráfico: uma guerra na guerra. São Paulo: Desatino, 2003.

Recebido em 3 de março de 2008 Aprovado em 28 de abril de 2008

\section{Estudos em Jornalismo e Mídia}

Ano V № 1 - 1o semestre de 2008 